\title{
Investigating Teachers' Views of Student-Centred Learning Approach
}

\author{
Ernest Lim Kok Seng ${ }^{1}$ \\ ${ }^{1}$ Taylor's Business School, Taylor's University, Lakeside Campus, Selangor, Malaysia \\ Correspondence: Ernest Lim Kok Seng, Taylor's Business School, Taylor's University, Lakeside Campus, 47500, \\ Subang Jaya, Selangor, Malaysia. Tel: 60-656-295-689. E-mail: kokseng.lim@taylors.edu.my
}

Received: July 11, 2013 Accepted: September 26, 2013 Online Published: June 27, 2014

doi:10.5539/ies.v7n7p143 URL: http://dx.doi.org/10.5539/ies.v7n7p143

\begin{abstract}
Conventional learning is based on low levels of students' participation where students are rarely expected to ask questions or to challenge the theories of the academic. A paradigm shift in curriculum has resulted in implementing student-centred learning (SCL) approach, putting students as the centre of the learning process. This mode of presentation has been implemented in the Malaysian classroom context. However, the shift in focus on learning from the conventional to the SCL has presented Malaysian educators with some challenges especially to move away from the 'chalk and talk' method of teaching used for decades in most classrooms in secondary schools. This study explores teachers' views of SCL approach through individual in-depth interviews. Various themes emerged from the interviews. The findings provides evidence that teachers who exposed students to some elements of SCL, saw students actively engaged in the learning process, aware of their own responsibilities, sense of autonomy inlearning and learned from their experiences. However, there were some challenges and constraints faced by teachers in implementing SCL approach.
\end{abstract}

Keywords: views, student-centred learning, conventional learning

\section{Introduction}

Student-centred learning (SCL) is based on the philosophy that the student is at the heart of the learning process (Machemer \& Crawford, 2007; Lea, Stephenson, \& Troy, 2003; Boyer, 1990). This is a notion which underlies all attempts at applying the SCL approach. Whilst this means that the student is the focal point of the process, the role of the teacher remains paramount, particularly when one considers that students are not all the same. According to Collins and O'Brien (2003), SCL is an instructional approach in which students influence the content, activities, materials, and pace of learning. This learning model places the student in the centre of the learning process. The instructor provides students with opportunities to learn independently and from one another and coaches the students in the skills they need to do so effectively. The SCL approach includes such techniques as substituting active learning experiences for lectures, assigning open-ended problems and problems requiring critical or creative thinking that cannot be solved by following text examples, involving students in simulations and role plays, and using self-paced and cooperative learning. Properly implemented SCL can lead to increase motivation to learn, greater retention of knowledge, deeper understanding, and more positive attitudes towards the subject being taught.

Some proponents of SCL assert that rather than devoting so much effort to teaching students what to think, SCL is based on the idea of teach them how to think (Tsui, 2002). Furthermore, within SCL there is an intrinsic motivation for learning, with the emphasis being on cooperation, rather than competition, between students. As part of this approach students are given the opportunity to compare their ideas with their peers and their teachers, whilst contributing to developing their curricula in a meaningful manner. In this context, the student is encouraged to ask questions and be inquisitive and the academic is seen as a facilitator and guide, rather than as the main source of knowledge. With the application of SCL approach in education, there is necessarily a shift in focus from academic teaching staff to the learner. This approach therefore changes the role of the teacher, from being entrusted with the 'transmission of knowledge to supporting and guiding self-regulated student learning' (Van Eekelen, Boshuizen, \& Vermunt, 2005). However, SCL is focused preliminary on the individual learner without considering the needs of the whole class. Besides individualism, Simon (1999)argues that Western learning approach may not be suitable for developing countries where there are limited resources, different learning cultures and large classes. 
SCL is an innovative learning approach that believes could increase student engagement in the learning process. Each student may require different ways of learning, researching and analysing the information available. Some students may require more support in embarking on a programme of studies that employs an SCL approach, particularly when it comes to making choices in their learning paths and in analysing the implications of any such choices. Others may already be accustomed to such an approach and need less assistance in this respect. As a group, students represent a wide range of opinions, abilities and strengths. SCL approach is an approach that puts the learner at the centre, it is only proper recognition of this diversity that empowers students to realize their full potential; engaging with their teachers and embarking on the learning process in the manner that will be most beneficial to them.

By its very nature, SCL allows students to shape their own learning paths and places upon them the responsibility to actively participate in making their educational process a meaningful one. By definition, the SCL experience is not a passive one, as it is based on the premise that 'student passivity does not support or enhance...learning' and that it is precisely "active learning" which helps students to learn independently (Machemer \& Crawford, 2007). In a SCL learning environment, learning is no longer confined to lecture theatres and there is more focus on peer-review and continuous self-assessment, together with a broader perspective and openness towards lifelong learning. This approach has many implications for the design and flexibility of curriculum, course content, and interactivity of the learning process.

The primary aim of this study is to investigate the views of the teachers about SCL, how it is being used during the teaching and learning process in the classroom and problems faced by teachers in implementing this method of teaching. Therefore, the objectives of this study are threefold. First, it seeks to determine the SCL approach perceived by teachers in the classroom. Then, it provides researcher with a general framework for SCL in the eyes of teachers and thirdly, it provides insight into the strengths and weaknesses of SCL as perceived by the teachers.

\section{Methodology}

\subsection{Respondents}

Primary data was gathered through interviews with 15 respondents. All the respondents were secondary schoolteachers from urban and suburban schools respectively. These teachers were teaching at public and private secondary schools. Their academic qualifications ranged from diploma to master with more than 10 years teaching experiences. The selection of respondents for this research was based on the fact that they were all experienced teachers who implemented some form of SCL in their teaching. Therefore, respondents were be able to give their views about their experiences in implementing SCL approach in the classroom. Permission was sought from all respondents and respondents were each given consent forms before the interview. All interviews were audio-taped with the consent of the interviewees.

\subsection{Interviews}

One-to-one interviews were carried out to understand the respondents' points of view and their experiences with regard to SCL approach. Interviews allowed the respondents to convey situations from their own views with their own words. Semi-structured were constructed and the questions were open-ended thus not limiting the respondents or interviewees choice of answers (Gubrium \& Holstein, 2002; McCracken, 1988). The purpose is to provide a setting or atmosphere where the interviewer and interviewee can discuss the topic in detail. The interviewer therefore can make use of cues and prompts to help and direct the interviewee into the research topic area thus being able to gather more in-depth or detailed data set (Creswell, 2003; McCracken, 1988; Patton, 2002).

Interviews were held in a quiet place that is the self-access room or the meeting room. Interviewees were reminded that their names were identified by pseudonyms throughout this paper and other identifying information would not be revealed for confidential purposes. All interviews were audio recorded with an average duration of 60 minutes. Respondents were asked about their understanding, definitions and beliefs in classroom practices relevant to teaching and their experiences when implementing this approach. An initial round of data analysis was done immediately after each interview. Interview questions were revised where necessary to further examine emerging issues.

\subsection{Data Analysis}

After transcription, data is organised into sections so that it can be easily retrieved. Each of the interviews was given a pseudonym from $T 1$ to $T 15$. In this study, familiarisation began when the researcher continuously listened to the interviews recorded digitally, transcribed and then listened to the interviews again, reading and 
re-reading when doing coding and categorising and later analysing the excerpts of the interviews for confirmation of coding, categorising and later when doing themes to come up with a thematic framework. In this research, transcribed interviews were analysed inductively. After completing each interview, codes and themes related to the research were developed. A coding scheme known as open coding system was developed based on patterns emerging from the interviews. Later, these codes were listed in a separate document chronologically. Next, codes were tabulated for frequency of appearance and listed accordingly. Finally, themes among codes were identified based on the categories of codes listed, as well as the frequency of each code in the notes.

\subsection{Validity and Reliability}

Additionally, several efforts were made to address validity and reliability issues in the qualitative data analysis. First, possible factual errors in the interview data were checked by cross-checking with each teacher interviewed of the selected schools. The transcribed interviews were sent to each respondent or interviewee for review. Second, for triangulating the interview data, some of the notes and information penned down in a memo during the interview sessions were also checked. Multiple sources were referred to including official documents from the schools and references such as journals and articles were used to further triangulate the data. The different interviewees' data was compared and tabulated; the data was viewed with some caution and restriction to identify the issues that seemed to be most potent or important to teachers when they implemented SCL, rather than attempting to identify belief systems or connections between particular pattern beliefs and implementation practices. The focus was then on investigation on developing an understanding of the variety of beliefs held by teachers on these issues.

\section{Research Results}

From the interviews, five different themes were uncovered from the 15 respondents. The five main themes in this study are:

\subsection{Students Learn Independently}

In SCL, the learner is given the opportunity to access to the materials without depending on the teacher. Students may also approach the materials through the teacher. Hence, students have personal choices in trying to access knowledge by themselves. This was agreed by eight of the respondents. Two of the teachers pointed out:

...The students will have opportunities to learn independently, give their views and learn from each other in classroom activities...(T1)

SCL approach is good as students takes full responsibility for his or her learning, participate actively in the lessons and understand what has been learned in a more meaningful way. (T10)

SCL allows students to discover the process of learning (Brown, 1994). Students work on their own to discover basic principle of knowledge (Woolfolk, 1998). This process of learning encourages a deeper understanding and stimulating higher level of thinking. Gibbs (1995) describes student-centred courses as those that emphasize on learner activity rather than teacher activity. This was concurred with one of the respondents who gave his views:

Well...the advantages of using SCL are....I may say many. As I have mentioned earlier, students feel that...their opinions are valued. When they feel that, they would feel would be motivated to learn. You know ...get involved in the learning process and participate actively or...be an active learner. (T7)

Likewise, Carlile and Jordan (2005) state that SCL encourages students to run their own activity, to discover and explore the underlying concept by themselves. Students are actively involved in the process of learning in order to promote a deep learning. This was clearly commented upon by the following respondent:

...students learn to give opinions. Also, this method helps to stimulate [and promote] students' minds to think deeply...you know...mm ... what is it?...critical... critically? Yes, yes...that's it. (T3)

\subsection{Autonomous Learner}

The SCL approach does not emphasize on delivering of knowledge to the students, instead it develops students' capacity and capability. This view is coincided with most dominant educational theorist who states the purpose of education is to cultivate individual's differences and develop their independence so as to motivate them to learn. One of the respondents pointed out:

SCL is more modern and is better suited for good and average students in good classes. Students in SCL would be able to acquire good thinking skills and be independent at the same time, learn to give their views among friends and come up with ideas to solve problems. (T2)

Students learnt to rethink their own roles as teacher, replacing tight control of learning with thoughtful 
facilitation of learning, gained confidence in the "guide on the side" role. This statement was agreed upon by the respondents as one of them said:

I ask them to find out information by providing a number of questions. Students will then in groups find the answers from the internet. Other students can ask each group questions based on their findings of the topic. (T5)

Rogers (1983) describes the shift in power from the expert teacher to the student learner. The respondents believed that this was indeed true and this was obvious from the statement made by one of the teachers:

It is a method of teaching which is current and the teacher is the facilitator. I also know that students will become independent learners ... yes...they have to be responsible for their own studies. (T3)

The personal skills in SCL that develop during group project may involve communication skills, teamwork skills, leadership and management skill, and problem solving skills. The respondents acknowledge that group work or pair work was indeed beneficial to the students as it promotes collaboration among learners and this was evident in the response given below:

I usually have group work and students ...They cooperate and work as a team.. to complete their task. Yes...Yes, I admit the class became quite noisy at times during activities but then students are [were] seen actively taking part in their learning. So, a little noise is okay, I guess...(T12)

It is speculated that focusing on content as early as in lower secondary school level will eventually leads student to have ability to gain knowledge through personal skills that have been developed. As a result, student performance and achievement will rise in both content knowledge and process of learning and leads to the production of excellent and responsible learners who are able to meet global demands. This was clearly commented upon by the following respondent:

...more involved in their learning. You know for ...like being more responsible for their learning and become more confident. Oh! They were at first a little unsure and scared. But later...they became more confident in finding information and giving views discussing and finding solutions to problems. (T5)

\subsection{Students Learn from Experiences}

In this type of learning that is SCL teachers act more like a facilitator whose role is to clarify and stimulate students' minds. Teachers should try where possible to help students use their own actual experiences (Carter \& Long, 1991). The respondents argue that students can bring in their past experiences and relate them to their learning and also they no longer must depend on the teacher to spoon-feed them and this the response from them:

Well... at the beginning... there was a lot of scepticism. You know the uneasy and unhappy feeling....You know...it is only natural after all these years of spoon-feeding. (T12)

....They can bring in their own past experiences and relate it to what they are learning especially when dealing with problem solving activities... or carrying out role plays or even when doing certain experiments...Well, most are related to real-life situations and so...the students could use their knowledge from their past experiences and relate it to the activities or work being done in class. (T13)

\subsection{Promote Equal Learning Opportunities}

SCL encourages the students to develop their own learning goals, thereby filling in the gaps in their knowledge or understanding (Boud \& Feletti, 1997). This element is concurred with one of the definitions stated in the SCL approach that dynamic interaction within the students in carrying out their given assignments. Respondents agreed that participating in discussions will inevitably help students acquire new learning skills:

This method does not emphasise too much on exams and students' hidden talents are unravelled or discovered. I'm totally surprised when I see them giving mature and good ideas in the student-centred activities. They are... able to think out of the box. (T4)

The relationship between learners is more equal in SCL, promoting growth and development. Students are doing more than the teachers; while others have a much broader definition which includes both of these concepts but, in addition, describes the shift in the power relationship between the student and the teacher. The respondents felt that it is a common scenario in most schools but with the use of ICT, more SCL is seen and this is one of the responses:

The teacher talks less...(laughs) and allows students talk time. The teacher is the facilitator guiding the students. Students are given the opportunity to learn independently. As students are allowed to give their views, they feel that their opinions or views are given prominence. (T10) 


\subsection{Challenges of SCL}

Edwards (2001) highlights the dangers associated with student-centeredness in education. The importance of the social context of learning and the value of interaction with peers is emphasized in the socio-cultural view of learning (Bredo, 1999). The concept of being an independent learner may in fact drive some of the sociability out of the learning process. Students who have experienced teacher-focused approaches may reject the SCL. However, 10 out of 15 respondents mentioned that large classes do not pose a problem to them to carry out SCL grouping activities as no mention of the financial aspects were mentioned. One of the responses was:

Hmm...well. I guess it should not be a problem. Mostly, SCL will have activities in pairs or in small groups. So... the only difference of a large class is, it will have more groups. (T3)

Other constraints mentioned was time factor whereby a lot of time is taken to carry out SCL activities and hinder from finishing the syllabus as mentioned by the respondent:

SCL does take up a bit of time...you know...so... a bit leceh [troublesome]...lah. However, students understand and remember better, so they are motivated to learn unlike the TCL method. So, SCL may hinder us from finishing our syllabus. (T6)

\section{Discussion and Conclusion}

The study provides evidence that teachers have exposed students to some elements of SCL approach. It appears that when SCL approach was used, students were actively engaged in the learning process. They were indeed learning and embracing elements of SCL such as engaging various types of active classroom learning strategies, enhancing their responsibility as students in knowledge construction and developing good relationship with teachers who acted as facilitators and were constantly guiding the students and prompting them to think independently and work collaboratively by providing learner-centred activities.

The study identifies the process of self-learning develops a deeper understanding and promotes higher importance on activity and independent learning. In SCL, teachers act more like facilitators whose role is to help students use their own actual experiences and relate them to their learning. Learning then becomes more meaningful as students can relate their experience to the new knowledge. There were some challenges to this method of learning. SCL activities takes a lot of time to be carried out and another downside to this method of learning is that not many activities can be carried out per year.

The autonomous learning approaches also enhance the development of skills in critical and analytical thinking that seem to be better developed than in the traditional setting. These learning approaches will promote education system for a sustainable future with a similar goal on improving academic and higher-order thinking skills to foster meaningful learning for the future and for life. The level of teachers' acceptance of the SCL approach manifests itself in the degree to which they are familiar to a different style of teaching and learning. In addition, the quality of educational facilities available to the student is an additional factor in determining the success of the SCL approach. Positive examples of change may however be counter-balanced by a resistance to SCL, by a large number of students and teachers in countries where the pace of change in teaching and learning has been rather slow across the past few decades, and rapid change is often difficult to implement (ESU, 2009)

In such cases, a major problem is the lack of will to make real meaningful change that challenges the current pedagogical underpinning of the education system. In this respect, if an attempt to set up an SCL approach introduced interactive learning and team work within the classroom, yet the mode of assessment remained a multiple choice tests based on a specific textbook, this limits the extent to which SCL will gain popularity and relevance for students is doubtful. It is clear that, in any SCL approach, one needs to take into the account the multiple roles of students-as partners in community of an education institution with their critical capability of contributing to this community and of choosing their learning path; as partners in subject-curriculum development for a better outcome to the learning process and; as a group in need of guidance in the best manner possible to able to draw, from the education community the best possible learning experience.

\section{References}

Boud, D., \& Feletti, G. (1997). The Challenge of Problem Based Learning. London: Kogan Page.

Boyer, E. B. (1990). Scholarship Reconsidered. Priorities of the Professoriate. New York: The Carnegie Foundation for the Advancement of Teaching.

Bredo, E. (1999). Reconstructing educational psychology. In P. Murphy (Ed.), Learners, Learning and Assessment. London: Open University Press.

Brown, H. D. (1994). Teaching by principle: An introductive approach to language pedagogy. Englewood Cliffs, 
New Jersey: Prentice Hall Reprints.

Carlile, O., \& Jordan, A. (2005). It works in practice but will it work in theory? The theoretical underpinnings of pedagogy. In S. Moore, G. O’Neill, \& B. McMullin (Eds.), Emerging Issues in the Practice of University Learning and Teaching. Dublin: AISHE.

Carter, R., \& Long, M. N. (1991). Teaching literature. Hong Kong: Longman.

Collins, J. W., \& O'Brien, N. P. (Eds.). (2003).Greenwood Dictionary of Education. Westport, CT: Greenwood.

Creswell, J. W. (1998). Qualitative inquiry and research design: Choosing among five traditions. Thousand Oaks, CA: Sage Publications.

Edwards, R. (2001). Meeting individual learner needs: Power, subject, subjection. In C. Paechter, M. Preedy, D. Scott, \& J. Soler (Eds.), Knowledge, Power and Learning. London: SAGE.

ESU. (2009). European Students' Union. Bologna with Student Eyes. Brussels.

Gibbs, G. (1995). Assessing Student Centred Courses. Oxford: Oxford Centre for Staff Learning and Development.

Gubrium, J. F., \& Holstein, J. A. (2002). From the individual interview to the interview society. In J. F. Gubrium, \& J. A. Holstein (Eds.), Handbook of InterviewResearch. Thousand Oaks, CA: Sage Publications.

Lea, S. J., Stephenson, D., \& Troy, J. (2003). Higher education students' attitudes to student-centred learning: Beyond 'educational bulimia'? Studies in Higher Education, 28(3), 321-334. http://dx.doi.org/10.1080/03075070309293

Machemer, P. L., \& Crawford, P. (2007). Student Perceptions of Active Learning in a Large Cross-Disciplinary Classroom. Active Learning in Higher Education, 8(1), 9-30. http://dx.doi.org/10.1177/1469787407074008

McCracken, G. (1988). The long interview. Thousand Oaks, CA: Sage Publications.

Patton, M. Q. (2002). Qualitative research \& evaluation methods (3rd ed.). Thousand Oaks, CA: Sage Publications.

Rogers, C. R. (1983). Freedom to Learn for the 80's. Columbus, Ohio: Charles E. Merrill Publishing Company.

Simon, B. (1999). Why no pedagogy in England? In J. Leach, \& B. Moon (Eds.), Learners and Pedagogy. London: Sage Publications.

Tsui, L. (2002). Fostering Critical Thinking through Effective Pedagogy: Evidence from Four Institutional Case Studies. The Journal of Higher Education, 73(6), 740-763. http://dx.doi.org/10.1353/jhe.2002.0056

Van Eekelen, I. M., Boshuizen, H. P. A., \& Vermunt, J. D. (2005). Self-Regulation in Higher Education Teacher Learning. Higher Education, 50, 447-471. http://dx.doi.org/10.1007/s10734-004-6362-0

Woolfolk, A. E. (1998). Educational psychology (7th ed.). Boston, MA: Allyn and Bacon.

\section{Copyrights}

Copyright for this article is retained by the author(s), with first publication rights granted to the journal.

This is an open-access article distributed under the terms and conditions of the Creative Commons Attribution license (http://creativecommons.org/licenses/by/3.0/). 